\title{
Oncolytic Viruses and Their Application to Cancer Treatment
}

\author{
Xie FZ and Zheng $L L^{*}$ \\ State Key Laboratory of Biocontrol and Key Laboratory of Gene Engineering of the Ministry of Education, \\ School of Life Sciences, Sun Yat-Sen University, China
}

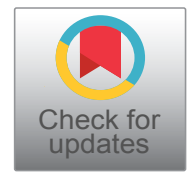

*Corresponding author: Zheng LL, State Key Laboratory of Biocontrol and Key Laboratory of Gene Engineering of the Ministry of Education, Biotechnology Research Center, Sun Yat-sen University, Guangzhou, 510275, P. R. China, Tel: 86-20-84112399

\begin{abstract}
Great progress has been achieved in the development of oncolytic viruses (OVs). Oncolytic therapy has become a feasible and effective treatment or supplementary method to cure cancer. This review summarizes the general condition of oncolytic therapy.
\end{abstract}

\section{Keywords}

Oncolytic virus, Oncolytic therapy, Cancer treatment, Clinical trial

\section{Introduction}

Early in the $20^{\text {th }}$ Century, a case was reported in The Lancet, that a notable decline in abnormal leucocyte of a female chronic-leukemia suffer was seen, and resulted in her unexpectedly improved condition, after her accidental infection of influenza virus. In 1912, Italian doctor Deface found that tumors of patients with cervical cancer would spontaneously shrink or regress if inoculated attenuated rabies vaccines. And this has raised the curtain on oncolytic virus therapy for tumors. Several more women have injected the same vaccine for treatment subsequently. However, all the patients died of the recurrence of cancer in the end.

Researchers started to experiment with mutant natural attenuated virus strains for treatment study upon cancer cells, after realizing that viruses might have inhibiting effects on tumors. West Nile viruses and adenoviruses were largely used for oncolytic therapy in the 1950s. In the 70s, reports claimed that varicella-zoster viruses' infection could ease acute lymphoblastic leukemia. Besides, measles viruses were found effective in curing leukemia, Burkitt lymphomas and Hodgkin lym- phomas, etc. But the mechanism remained unknown and therefore cannot be properly used for tumor treatment. Also, scientists were a lack of tools for modifying more effective virus strains. Whereas chemotherapeutics was comparatively safer and more well-known, doctors preferred chemotherapy more. Thus, oncolytic therapy was always at the secondary position in the cancer study.

The feature and mechanism of various kinds of virus genes are gradually known as the development of virology and genetic. Advancement in techniques like genetic engineering allows people to take directed operation and modification upon virus genes, so as to manipulate virus behavior and function. Directed operation and modification have been taken upon some specific viruses since the 1990s. Over ten kinds of oncolytic viruses aiming at varied types of cancers are now in different preclinical trial phases. China approved world's first oncolytic virus therapy for cancer treatment in 2006, by using $\mathrm{H} 101$ for cancers of the head and neck [1].

\section{Mechanism}

a) Viruses interact with specific cell-surface receptors. As tumor cells overexpressed these proteins than normal cells did, the virus will probably infect the tumor cell.

b) After binding to the cell surface receptor, the virus is internalized by endocytosis or membrane fusion, releases its genome into the cell. Replication and viral gene expression vary according to the type of the virus. It can take place entirely in the cell cytoplasm (such as for vesicular stomatitis virus), or in the nucleus and

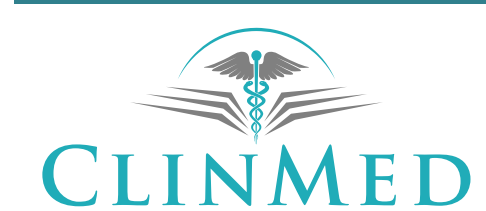

INTERNATIONAL LIBRARY ir

Citation: Xie FZ, Zheng LL (2019) Oncolytic Viruses and Their Application to Cancer Treatment. Int Arch Clin Pharmacol 5:020. doi.org/10.23937/2572-3987.1510020

Accepted: August 22, 2019: Published: August 24, 2019

Copyright: (c) 2019 Xie FZ, et al. This is an open-access article distributed under the terms of the Creative Commons Attribution License, which permits unrestricted use, distribution, and reproduction 
cytoplasm (such as for adenovirus). In either case, viral gene expression and synthesis of viral proteins largely depends on cellular machinery. Viral gene expression and replication trigger cellular antiviral defenses, such as apoptosis, which are often inactivated in tumor cells. Expression of viral proteins will eventually lead to immune-mediated lysis of infected cells. Lysis is directed by CD8+ T cells, which recognize viral peptide epitopes that are presented by major histocompatibility complex (MHC) class I molecules on the surface of the infected cell. Also, lysis may be triggered because of an overwhelming amount of budding and release of progeny virions from the cell surface, or by the activation of apoptosis during the course of viral replication and gene expression [2].

\section{Some Oncolytic Viruses That Been Tested In} Preclinical Trials

\section{Ad(adenovirus)}

At present, the main strategy of modifying adenovirus's tumor targeting and transfection efficiency is to make use of some abnormal performance of expression of tumor biology. One method is partly or entirely deletion of the gene which are unnecessary in the replication of tumor cells. Another one is to modify the necessary genetic expression during virus replication with tumor-specific promotor or enhancer [3].

ONYX-015 modified by American Onyx Company is an E1B-55K-deleted adeno-virus. Onyx-015 lacks the E1B$55 \mathrm{~K}$ gene product, which is normally required for degrading the cellular p53 protein during viral infections, allowing it to only replicate in and destroy cells that lack p53, such as tumor cells. At present, ONYX-015 has the most complete and detailed data in clinical trials which involve many solid tumor-like cancers of the head and neck, pancreatic cancer, malignant gliomas, colorectal cancer, prostate cancer, ovarian cancer. Many basis and clinical research have been done on the intent to enhance the replication specificity of $A D$ in tumor and the activity which required in organism against tumor. For instance, the use of Ad alone or co-expression of GMCSF, IL-12 and IL-18 and other immunomodulatory genes in order to promote the anti-tumor activity of the body. Insertion of the telomerase promoter to enhance the replication selectivity or transform adenovirus. Ongoing clinical trials now include CGTG-102(with expression of GM-CSF) treat advanced solid tumors alone or with cyclophosphamide administration intratumor or intravenous. DNX-2401 (Delta-24-RGD-4C) treat glioblastoma and neuroglioma. (NCT00805376;NCT01582516). Intravesical instillation treat balder cancer. (NCT01438112).

\section{Reovirus}

Reovirus infection occurs often in humans, but most cases are mild or subclinical. Reoviruses can also affect the gastrointestinal system (such as Rotavirus) and respiratory tract. The virus can be readily detected in feces, and may also be recovered from pharyngeal or nasal secretions, urine, cerebrospinal fluid, and blood. Their role in human disease or treatment is still uncertain, but demonstrate a certain oncolytic property. Though reoviruses' molecular mechanism of selective infection and tumor cell destruction is remaining to be studied, it's generally considered that the activation of RAS signal pathway plays a key role in selective oncolytic effect mediated by this virus.

\section{$\mathrm{MV}$ (measles virus; paramyxovirus)}

Many researches have been done to prove the killing activity of MV on prostate, mesothelial, ovarian cancer. Heinzerling's research proved it. In a phase I dose escalation trial, 5 patients with CTCL received 16 intratumorally injections of live MV, Edmonston-Zagreb vaccine strain. The well tolerated treatment with $\mathrm{MV}$ resulted in clinical responses. Evaluation of biopsies, by immunohistochemistry and RT-PCR demonstrated local viral activity with positive staining for MV NP protein. All patients demonstrated an increased anti-measles antibody titer after therapy. One of the treated lesions completely disappeared [4].

Mayo Clinic has developed MV (MV-CEA \& MVNIS) that carry the gene that coding carcino embryonie antigen and sodium iodide symporter. MV-NIS is engineered to express the marker peptide carcinoembryonic antigen to permit real-time monitoring of viral gene expression in tumors. Patients with Taxol and platinum-refractory recurrent ovarian cancer and normal CEA levels were eligible for MV-CEA phase I trial. Twenty-one patients were treated with MV-CEA i.e.14 of 21 patients responded dose-dependent stable disease. Five patients had significant decreases in CA-125 level [5]. There are 5 Phase 1 clinical trials carrying on by Mayo Clinic now (NCT00408590, NCT00390299, NCT01503177, NCT01846091, NCT00450814), involving ovarian cancer, peritoneal cancer, glioblastoma multiforme tumors, malignant pleural mesothelioma, head and neck squamous cell carcinoma and multiple myeloma. Routes of administration include intratumorally, intrapleural, intraperitoneal or residual tumor resection cavity injection. Therapy options are alone or in combination with cyclophosphamide treatment [5].

\section{HSV-1 (Herpes Simplex Virus 1)}

$\mathrm{HSV}-1$ is attractive for cancer therapy because of the following characteristics: (a) It infects a broad range of cell types and species, killing tumor cells at a relatively low multiplicity of infection (MOI); (b) The infection can't be affected by the antibody in blood which makes repeated injection won't weaken its efficiency; (c) The well-characterized large genome $(152 \mathrm{~kb})$ contains many nonessential genes that can be replaced (up to $30 \mathrm{~kb}$ ) with multiple therapeutic transgenes; (d) Many antiherpetic drugs are available as a safeguard against 
unfavorable replication of the virus; and (e) The virus remains as an episome within the infected cell, even during latency, precluding insertional mutagenesis [6].

G207 was constructed as a second-generation vector with both copies of $\gamma 34.5$ deleted and the ICP 6 gene inactivated. ICP6 encode a large subunit of ribonucleotide reductase. The enzyme is the key and rate limiting enzyme of DNA synthesis and repair, which plays a crucial part in DNA replication and amplification. Therefore, the second generation obtained tumor cell targeting with double insurance [7].

$\mathrm{G} 47 \Delta$ is a third-generation vector that was constructed from $\mathrm{G} 207$ by deletion of the ICP47 gene, which normally blocks MHC class I-mediated antigen presentation in infected cells. Consequently, human melanoma cells infected with $\mathrm{G} 47 \mathrm{\Delta}$ expressed higher levels of MHC class I on their surface, compared to G207-infected cells, resulting in enhanced stimulation of tumor-infiltrating lymphocytes [7]. G47 $\Delta$ is safer and more effective, it has better performance in treating malignant brain tumors, prostate cancer and breast cancer. A considerable result in suppression and oncolytic effect in metastatic breast cancer, nasopharyngeal cancer, liver cancer and thyroid cancer treatment [8].

\section{NDV (Newcastle-disease Virus)}

In 2009 Schumacher [9] observed a strong inverse correlation between the susceptibility to infection and the basal expression of the antiviral genes RIG-I, IRF3, IRF7 and IFN- $B$. A strong expression of these genes can explain the resistance of normal cells to NDV infection and a weak antiviral gene expression the broad susceptibility of tumor cells. Thus, NDV can massive amplify in the tumor cell and specifically kill tumor cells without infecting normal cells. What's more, many of tumor cells have a higher expression of sialic acid, which is a receptor of NDV. Though the combination with the widely distributed sialic acid residues on the cell surface, NDV can get into cells and thus kill various kinds of tumor cells. NDV mediates apoptosis mainly through the endogenous apoptotic pathway and does not rely on the involvement of the apoptotic pathway of interferon. In 2010 Bier [10] performed a siRNA-based screen of genes, which are known or predicted to participate in membrane trafficking/remodeling, to reveal Ras-related or Ras-independent NDV-sensitizers in the tumorigenic RT3 $\mathrm{K} 1$ cells that may also be drivers of tumorigenesis. Rac1 is an essential protein for efficient replication of oncolytic NDV in the tumorigenic cells.

With the reverse genetics' technology matures, the technology began to be applied to optimize the effect of oncolytic Newcastle disease virus. By reverse genetics technique recombinant NDV, can express an exogenous tumor-killing factor, with excellent tumor-killing ability, and achieved a good therapeutic effect in clinical trials.

\section{VV (vaccinia virus; poxvirus)}

Vaccinia virus played a decisive role in helping the human smallpox virus. With the rapid development of molecular biology, virology, immunology and cancer genetics, vaccinia virus becomes a great choice due to its effective infection to a wide range of cells, highly immunogenic, the ability to accommodate a large amount of gene inserted and correctly express them and cytoplasmic replication without the possibility of chromatin integration. Meanwhile, as the longest and most widely used virus in human history, a complete study on it provided a convenient further use. The main uses of vaccinia virus are (a) As a delivery vector for cancer; (b) As a carrier of vaccine for immune regulatory molecules and tumor associated antigens in cancer immunotherapy; (c) As oncolytic media replicate in selected cells and lead to cell lysis. The main method to treat cancer with vaccinia virus is making tumor cells originally disguised with specific surface antigens reassigned to the targeted clusters through the partial activation of the stronger immune response, and then eliminated by macrophages [11]. Table 1 summarized the above oncolytic virus details and their development status (Table 1).

\section{Advantages and Disadvantages between On- colytic Therapy \& Traditional Therapy}

Table 1: Clinical development of oncolytic viral vectors.

\begin{tabular}{|c|c|c|c|}
\hline Virus & Description & Mechanism & Clinical Condition \\
\hline Adenovirus & $\begin{array}{l}\text { medium-sized ( } 90-100 \mathrm{~nm} \text { ), } \\
\text { nonenveloped (without an } \\
\text { outer lipid bilayer) viruses with } \\
\text { an icosahedral nucleocapsid containing } \\
\text { a double stranded DNA genome }\end{array}$ & $\begin{array}{l}\text { tumor antigens } \\
\text { targeting, } \\
\text { conditionally replication }\end{array}$ & $\begin{array}{l}\text { ColoAd1 from PsiOxus Therapeutics has } \\
\text { entered Phase I/II clinical study with its } \\
\text { oncolytic vaccine. } \\
\text { ONYX-015 are used in combination with the } \\
\text { standard chemotherapeutic agents cisplatin } \\
\text { and } 5 \text {-fluorouracil to combat head and neck } \\
\text { tumors. } \\
\text { the Chinese State Food and Drug } \\
\text { Administration approved H101, an oncolytic } \\
\text { adenovirus similar to Onyx-015 (E1B-55K/ } \\
\text { E3B-deleted), for use in combination with } \\
\text { chemotherapy for the treatment of late-stage } \\
\text { refractory nasopharyngeal cancer. }\end{array}$ \\
\hline
\end{tabular}




\begin{tabular}{|c|c|c|c|}
\hline Reovirus & $\begin{array}{l}\text { non-enveloped viruses' range between } \\
70-80 \text { nm, dsRNA composed of ten } \\
\text { segments, } \\
87 \text { species in this family, divided among } \\
30 \text { genera. Most infections are mild or } \\
\text { subclinical. }\end{array}$ & $\begin{array}{l}\text { selectively infects } \\
\text { RAS-transformed cells }\end{array}$ & $\begin{array}{l}\text { Reovirus phase I clinical trials have shown } \\
\text { indications of efficacy, and several phase II/III } \\
\text { trials are ongoing at present. } \\
\text { Reovirus's extensive preclinical efficacy, } \\
\text { replication competency, and low toxicity } \\
\text { profile in humans have placed it as an } \\
\text { attractive anticancer therapeutic }\end{array}$ \\
\hline $\begin{array}{l}\text { Measles } \\
\text { Virus }\end{array}$ & $\begin{array}{l}\text { single-stranded, negative-sense, } \\
\text { enveloped (non-segmented) RNA virus } \\
\text { of the genus Morbillivirus within the } \\
\text { family Paramyxoviridae. }\end{array}$ & $\begin{array}{l}\text { tumor antigens re- } \\
\text { targeting, } \\
\text { higher CD46 densities } \\
\text { typical of tumor cells, } \\
\text { infection leads to } \\
\text { extensive cell fusion. }\end{array}$ & $\begin{array}{l}\text { Phase I conducted } \\
\text { Two patients with glioblastoma multiforme } \\
\text { have so far been enrolled into the } \\
\text { intracerebral MV-CEA study and six patients } \\
\text { with multiple myeloma have been enrolled for } \\
\text { intravenous administration of MV-NIS at two } \\
\text { dose levels }\end{array}$ \\
\hline $\begin{array}{l}\text { Herpes } \\
\text { Simplex } \\
\text { Virus } 1\end{array}$ & $\begin{array}{l}\text { large double-stranded, } \\
\text { linear DNA genome } \\
\text { enveloped viruses }\end{array}$ & $\begin{array}{l}\text { Only replicates in } \\
\text { tumor cells }\end{array}$ & $\begin{array}{l}\text { Phase I clinical traits of three vectors, G207, } \\
1716 \text {, and NV1020, are either ongoing or } \\
\text { completed, with no adverse events attributed } \\
\text { to the virus. These and other HSV-1 vectors } \\
\text { are effective against a myriad of solid tumors } \\
\text { in mice } \\
\text { Interim overall survival data from Amgen's } \\
\text { phase } 3 \text { trial of a genetically-attenuated } \\
\text { herpes virus suggests efficacy against } \\
\text { melanoma. }\end{array}$ \\
\hline $\begin{array}{l}\text { Newcastle- } \\
\text { disease } \\
\text { Virus }\end{array}$ & $\begin{array}{l}\text { contagious bird disease } \\
\text { a negative-sense, single-stranded RNA } \\
\text { virus }\end{array}$ & $\begin{array}{l}\text { selectively replicates } \\
\text { in interferon-defective } \\
\text { cells }\end{array}$ & $\begin{array}{l}\text { In } 1999 \text {, promising results were reported } \\
\text { using an attenuated strain of the Newcastle } \\
\text { virus } \\
\text { In } 2006 \text {, NDV-HUJ, which showed promising } \\
\text { results in } 14 \text { glioblastoma multiforme patients. } \\
\text { In } 2013 \text {, NDV may prove to be an attractive } \\
\text { oncolytic agent for cancers resistant to } \\
\text { multiple chemotherapeutic agents. }\end{array}$ \\
\hline $\begin{array}{l}\text { Vaccinia } \\
\text { Virus }\end{array}$ & $\begin{array}{l}\text { large, complex, enveloped virus } \\
\text { belonging to the poxvirus family. } \\
\text { Linear, double-stranded DNA genome } \\
\text { approximately } 190 \text { kbpin length, } \\
\text { and which encodes approximately } \\
250 \text { genes. Roughly } 360 \times 270 \times 250 \\
\mathrm{~nm} \text {, approximately } 5-10 \mathrm{fg} \text {. }\end{array}$ & $\begin{array}{l}\text { Gain access to tumor } \\
\text { through vascular } \\
\text { leakiness }\end{array}$ & $\begin{array}{l}\text { phase I-II clinical trials have been performed } \\
\text { with IFN- } \beta \text { in patients with brain tumors and } \\
\text { other metastatic solid tumors. } \\
\text { overall efficacy was limited and transient, and } \\
\text { significant systemic toxicities limited further } \\
\text { dose escalation } \\
\text { combining IFN-dependent cancer selectivity } \\
\text { with IFN- } \beta \text { expression to achieve tumor- } \\
\text { specific replication, IFN- } \beta \text { gene expression, } \\
\text { and efficacy following systemic delivery in } \\
\text { preclinical models. }\end{array}$ \\
\hline
\end{tabular}

OVs have many features that make them advantageous and distinct from current therapeutic modalities: (i) OVs often target multiple oncogenic pathways and apply multiple means for cytotoxicity which means the generation of resistance is at a low probability (not seen so far); (ii) OVs replicate in a tumor-selective manner and are non-pathogenic, in fact, only minimal systemic toxicity has been detected; (iii) Virus dose in the tumor increases with time due to virus amplification, which is opposed to classical drug pharmacokinetics that decreases with time; (iv) Safety features can be built in, such as drug and immune sensitivity. These features could result in a very high therapeutic index [12].

Meanwhile, viruses can trigger several spectator mechanisms to kill uninfected cancer cells. OVs can infect tumor pericytes, which elicits a constrictive inflammatory response that slows blood flow to the tumor, or OVs help present tumor associated antigens to the immune system and engage antitumor immunity [13].
However, the crucial problem over oncolytic therapy is the efficiency of the drugs delivery to the specified location. There are two main ways of administration. Intratumorally injection requires higher techniques and it's useless due to tumor's systemic metastasis and diffusion growth. Systemic intravenous injection is easier to implement and aims at several tumor, but it also has many disadvantages. (a) The existence of non-immune serum which is pre-existing or accumulated through multiple administrations can kill the viruses or cause sequestration in the liver. (b) Lack of effective extravasation pathway to transfer from the internal environment into the cell. (c) Cell carriers (i.e., mesenchymal stromal cells, myeloid-derived suppresser cells (MDSCs), neural stem cells, T cells, cytokine-induced killer cells, or irradiated tumor cells) can shield virus from neutralization and facilitate virus delivery to the tumor.

Therefore, the effectiveness depends on the cell 
phenotype, permissiveness to virus infection, tumor homing ability, and transfer of infectious virus to tumor cells [12].

\section{Development Prospect}

As the situation stated above, there are several recent approaches to improve oncolytic virus delivery.

\section{Targeting the Tumor Cell Surface}

During tumor evolution, various genetic and epigenetic events result in the unique display or overexpression of so-called 'tumor antigens' on the surface of malignant cancer cells. As cell surface recognition and virus entry are the first procedure in a productive viral infection, engineering a virus which can specific recognize the tumor cell surface would restrict replication of a potent oncolytic virus to malignant cancer cells [2].

\section{Exploiting the Tumor Microenvironment}

Given that virally encoded receptors are highly evolved proteins, an alternative approach is to use the in vivo tumor environment to augment selectivity without the complete re-engineering of an already efficient system. For example, subtle alterations in the fusion (F)-protein of measles virus allow it to be processed to an active form only in the protease-rich tumor microenvironment. The F-protein of measles virus facilitates viral entry into cells by mediating fusion of the viral and cellular membranes [2].

Non-enveloped viruses is another option. For example, reovirus normally infects cells of the gastrointestinal tract, where proteases can convert the non-infectious reovirus into an infectious form called the intermediate sub-viral particle (ISVP). When given intravenously, reovirus is not efficiently processed to the infectious form. However, it is possible to select variants that have been converted into ISVP by the action of proteases that are overexpressed in the tumor microenvironment. These selected reoviruses have been shown, in vivo, to selectively infect and kill malignant lymphoid cells that produce a protease-rich microenvironment [14].

\section{'Naturally Smart' Viruses}

Viruses have evolved to gain access to the cell through binding to proteins that are displayed on the plasma membrane and that often have crucial roles in regulating normal cell proliferation, homeostasis or adhesion [2]. Recognizing this, Darren Shafren's group have screened a collection of picornaviruses in a search for viruses that preferentially infect tumor cells, based on their overexpression of natural virus receptors [15].

\section{Tumor Growth and Innate Immunity}

Innate immunity is a non-specific defense mechanism which is triggered immediately after pathogen detection and does not develop immunological memory for antigens. OVs can be modified to make better use of innate and adaptive responses to eliminate tumor cells [2].

One strategy to develop oncolytic therapeutics is to select or design viruses that are especially sensitive to the antiviral properties of interferons. Such viruses should have their replication strongly suppressed in interferon-responsive normal tissues but still be able to amplify in interferon-nonresponsive tumor cells. The tumor-selective oncolytic activity could be achieved by deleting or attenuating gene which encode these antiinterferon-gene products [16].

Another common defect in tumor cells that might make them susceptible to oncolytic virus activity involves the downregulation of p53 or its downstream targets. Mice with supernumerary copies of the normal Trp53 gene are both more resistant to VSV infection and have a decreased incidence of tumor formation [17].

Another design strategy for oncolytic viruses would be to delete viral anti-apoptotic genes, creating mutants that only replicate in apoptosis-deficient tumor cells [18].

\section{Diplomatic Immunity}

The mammalian adaptive immune system has evolved to restrict the replication and spread of invading pathogens. For oncolytic virus-based therapeutics, this is a double-edged sword. On the one hand, these defense mechanisms block the delivery and/or spread of oncolytic viruses. On the other hand, viral stimulation of the adaptive immune system seems to activate anti-tumor immune surveillance systems, increasing the effectiveness of oncolytic virus therapy. Oncolytic viruses not only mediate direct tumor oncolysis, but also, in combination with their inherent adjuvant properties, induce or reactivate cancer immune surveillance programs. These phenomena indicate that: First, it might not be crucial for the oncolytic virus alone to completely eradicate a tumor to be therapeutically effective. Rather, if the virus can quickly establish a tumor-specific infection, this will lead to a localized inflammation, in situ cytokine production and ultimately an anti-tumor immune response. Second, oncolytic viruses that have been engineered to produce immune stimulatory factors on infection of tumor cells may be more effective therapeutics [2].

\section{Conclusion}

Study on oncolytic viruses not only contributes to cancer treatment, but also reveals much upon how cells regulate genetic expression [2]. In spite of considerable improvement in the last two decades, further progress is needed in oncolytic virus therapy for cancers. Methods include equipping oncolytic virus with therapeutic genes; optimizing traditional chemotherapy and radio- 
therapy with combination of oncolytic therapy; adjust body immune response to achieve minimal antiviral effect with maximum anti-tumor effect.

\section{Acknowledgments}

This research is supported by the grants from the $\mathrm{Na}$ tional Natural Science Foundation of China: 31401975 (to L.-L.Z.). This research is supported in part by the Guangdong Province Key Laboratory of Computational Science and the Guangdong Province Computational Science Innovative Research Team. The authors declare no conflict of interest.

\section{References}

1. Garber K (2006) China approves world's first oncolytic virus therapy for cancer treatment. J Natl Cancer Inst 98: 298300.

2. Parato KA, Senger D, Forsyth PA, Bell JC (2005) Recent progress in the battle between oncolytic viruses and tumours. Nat Rev Cancer 5: 965-976.

3. Guse K, Hemminki A (2009) Cancer gene therapy with oncolytic adenoviruses. J BUON 14: S7-S15.

4. Heinzerling L, Künzi V, Oberholzer PA, Kündig T, Naim H, et al. (2005) Oncolytic measles virus in cutaneous T-cell lymphomas mounts antitumor immune responses in vivo and targets interferon-resistant tumor cells. Blood 106: 2287-2294.

5. Galanis E, Hartmann LC, Cliby WA, Long HJ, Peethambaram PP, et al. (2010) Phase I trial of intraperitoneal administration of an oncolytic measles virus strain engineered to express carcinoembryonic antigen for recurrent ovarian cancer. Cancer Res 70: 875-882.

6. Varghese S, Rabkin SD (2002) Oncolytic herpes simplex virus vectors for cancer virotherapy. Cancer Gene Ther 9: 967-978.

7. Mineta T, Rabkin SD, Yazaki T, Hunter WD, Martuza RL, et al. (1995) Attenuated multi-mutated herpes simplex virus-1 for the treatment of malignant gliomas. Nat Med 1: 938-943.
8. Wong HH, Lemoine NR, Wang Y (2010) Oncolytic viruses for cancer therapy: Overcoming the obstacles. viruses 2 : 78-106.

9. Wilden H, Fournier P, Zawatzky R, Schirrmacher V (2009) Expression of RIG-I, IRF3, IFN-beta and IRF7 determines resistance or susceptibility of cells to infection by newcastle disease virus. Int J Oncol 34: 971-982.

10. Puhlmann J, Puehler F, Mumberg D, Boukamp P, Beier $R$ (2010) Rac1 is required for oncolytic NDV replication in human cancer cells and establishes a link between tumorigenesis and sensitivity to oncolytic virus. Oncogene 29: 2205-2216.

11. Shen $Y$, Nemunaitis J (2005) Fighting cancer with vaccinia virus: teaching new tricks to an old dog. Mol Ther 11: 180195.

12. Chiocca EA, Rabkin SD (2014) Oncolytic viruses and their application to cancer immunotherapy. Cancer Immunol Res 2: 295-300.

13. Mahoney DJ, Stojdl DF (2012) Fighting fire with fire: Rewiring tumor cells for oncolytic virotherapy. Future Oncol 8: 219-221.

14. Van Themsche C, Potworowski EF, St-Pierre Y (2004) Stromelysin-1 (MMP-3) is inducible in T lymphoma cells and accelerates the growth of lymphoid tumors in vivo. Biochem Biophys Res Commun 315: 884-891.

15. Shafren DR, Sylvester D, Johansson ES, Campbell IG, Barry RD (2005) Oncolysis of human ovarian cancers by echovirus type 1. Int J Cancer 115: 320-328.

16. Stojdl DF, Lichty BD, tenOever BR, Paterson JM, Power AT, et al. (2003) VSV strains with defects in their ability to shutdown innate immunity are potent systemic anti-cancer agents. Cancer Cell 4: 263-275.

17. Munoz-Fontela C, Garcia MA, Garcia-Cao I, Collado M, Arroyo J, et al. (2005) Resistance to viral infection of super p53 mice. Oncogene 24: 3059-3062.

18. Liu TC, Hallden G, Wang Y, Brooks G, Francis J, et al. (2004) An E1B-19 kDa gene deletion mutant adenovirus demonstrates tumor necrosis factor-enhanced cancer selectivity and enhanced oncolytic potency. Mol Ther 9: 786-803. 